\title{
RUOKOHELVEN TUOTANTO- JA TOIMITUSKETJU JA KÄYTTÖ POLTTOAINEENA VOIMALAITOKSISSA
}

\author{
Teuvo Paappanen ${ }^{1)}$, Tuulikki Lindh ${ }^{1)}$, Janne Kärki ${ }^{1)}$, Risto Impola ${ }^{1)}$ \\ Samuli Rinne ${ }^{2)}$ \\ 1) VTT, PL 1603, 40101 Jyväskylä, etunimi.sukunimi@vtt.fi \\ 2) YTY-konsultointi, Teljintie 4, 40530 Jyväskylä, samuli.rinne@suomi24.fi
}

\section{Tiivistelmä}

Ruokohelven käyttö voimalaitoksissa polttoaineena on voimakkaasti lisääntymässä. Helven tuotanto- ja toimitusketjua on kehitetty, mutta teknisiä ratkaisuja ja toimintatapoja voidaan vielä tehostaa. Suurimmat kehityskohteet ovat korjuutappioiden pienentäminen, kaukokuljetuksen tehostaminen, paalien murskauksen kehittäminen (silpun laatu ja murskauksen kapasiteetti) sekä voimalaitosten tekniikan ja toimintatapojen parantaminen.

Ruokohelven tiheys kuljetuksissa on pieni ja tästä johtuen rekka-auton täyttä kantavuutta, 35 37 tonnia ei useinkaan saavuteta. Irtotavaran tiheys on korkeintaan $75 \mathrm{~kg} / \mathrm{m}^{3}$. Kiinteäkammioisen pyöröpaalaimen paalien tiheys on noin $140 \mathrm{~kg} / \mathrm{m}^{3}$. Muuttuvakammioisilla paalaimilla tiheydet ovat 145 $180 \mathrm{~kg} / \mathrm{m}^{3}$. Joissakin tapauksissa on suurkanttipaalaimilla saavutettu jopa yli $200 \mathrm{~kg} / \mathrm{m}^{3}$ tiheyksiä. Irtotavarakuorman massa on korkeintaan 10,5 tonnia. Pyöröpaalikuorman massat ovat $15-18$ tonnia ja suurkanttipaalien 20 - 22 tonnia. Esimerkiksi irotavaran kuljetus $50 \mathrm{~km}$ matkalla maksaa noin 6 $€ / M W h$ ja eri tyyppisten paalien $3-4,5 € / M W h$.

Paalien murskauksen neljä ongelmakohtaa ovat murskainta tukkivat paalinarut, pitkä silpun pituus, pölyäminen ja murskauksen kustannus. On olemassa murskaimia, joissa teknisen ongelmat on voitu ratkaista, mutta murskaus on suhteellisen kallista, $3-4 € / M W h$. Tällaisia ovat esimerkiksi kuorma-autoalustaiset vasaramurskaimet ja kaukolomurskaimet. Halvimmillaan murskaus voidaan tehdä voimalaitoksen kiinteällä murskalla, mutta tällöin murskain on pois puun murskauksesta, jossa se on tehokkaimmillaan. Maatalouden paalisilppurit soveltuvat vaihtelevasti paalien murskaukseen: joissakin malleissa paalinarujen kietoutuminen roottorin ympärille on todellinen ongelma, joissakin vähäisempi ongelma.

Suomessa on yli 75 voima- ja lämpölaitosta, jotka arvion mukaan pystyisivät käyttämään helpeä 4,1 TWh, mikä viljelypinta-alana on 140000 - 190000 ha. Yli 20 voimalaitoksella on Suomessa kokemusta ruokohelven soveltuvuudesta energiantuotantoon. Hetkellinen helven maksimiosuus on ollut $10-15 \%$ energiasisällöstä ja keskimääräinen osuus $1-3 \%$. Käytön ensikokemusten perusteella ruokohelpi ei ole aivan ongelmaton polttoaine. Erilaiset tukkeentumiset ja holvaantumiset ovat ongelmana. Pienestä energiatiheydestä johtuen helpeä ei aina voida käyttää maksimitehon aikana, ja helven epäillään likaavan ja syövyttävän kattiloita. Yksi ratkaisu ongelmiin voi olla Tanskan mallin mukainen hidaskäyntinen, kevyt murskain ja pneumaattinen siirto kattilaan. Tätä on tarkoitus kokeilla Kokkolan Voima Oy:n laitoksella loppuvuodesta 2007.

Helven tyyppillinen kokonaistuotantokustannus pyöröpaaleina on noin $26 € / M W h$. Kustannus sisältää viljelyn, korjuun, kaukokuljetuksen $(70 \mathrm{~km})$ ja paalien murskauksen voimalaitoksella. Viljelijän kustannus on noin $24 € / \mathrm{MWh}$. Kun otetaan huomioon maataloustuet on viljelijän saatava vähintään $3 € / M W h$ voimalaitokselta. Tämä ei vielä tuo voittoa viljelijälle. Jos viljelijä haluaa $170 € /$ ha voittoa ( $6 € / M W h$ ), olisi voimalaitoksen maksama hinta oltava $9 € / M W h$. Päästökauppatilanteessa, kun helpi korvaa kivihiiltä tai turvetta, tulisi voimalaitoksen hyvinkin pystyä maksamaan tämä hinta, olettaen että helvestä ei aiheudu ylimääräisiä kustannuksia voimalaitokselle.

Asiasanat: bioenergia, peltoenergia, ruokohelpi, voimalaitospolttoaine 


\section{Johdanto}

Ruokohelpi on yksi lupaavimmista peltoenergiakasveista. Ruokohelven tuotanto- ja käyttöketjun kehittämiseksi ovat VTT, MTT ja Työtehoseura toteuttaneet Climbus-ohjelman projektia "Ruokohelven polttoaineketjujen kehittäminen liiketoimintamahdollisuuksien parantamiseksi". Projektissa on kehitetty korjuuta, kaukokuljetusta, murskausta ja sekoitusta ja käyttöä voimalaitoksilla. Tässä esityksessä on tarkasteltu korjuun jälkeisiä työvaiheita ja niihin liittyvää kehitystyötä.

\section{Tulokset ja tulosten tarkastelua}

\section{Ruokohelven kuljetus}

Ruokohelpeä voidaan kuljettaa irtotavarana, paaleina tai seoksena turpeen tai hakkeen kanssa. Ruokohelven tiheys kuljetuksissa on pieni ja tästä johtuen rekka-auton täyttä kantavuutta, 35 - 37 tonnia ei useinkaan saavuteta. Irtotavaran tiheys on korkeintaan $75 \mathrm{~kg} / \mathrm{m}^{3}$. Kiinteäkammioisen pyöröpaalaimen paalien tiheys on noin $140 \mathrm{~kg} / \mathrm{m}^{3}$. Muuttuvakammioisilla paalaimilla tiheydet ovat $145-$ $180 \mathrm{~kg} / \mathrm{m}^{3}$. Joissakin tapauksissa on suurkanttipaalaimilla saavutettu jopa yli $200 \mathrm{~kg} / \mathrm{m}^{3}$ tiheyksiä. Useiden paalityyppien yksi mitta on 1,2 m, joten rekka-auton kuormatilan leveyden on oltava joitakin senttejä yli 2,4 m, jotta paaleja voidaan laittaa kaksi rinnakkain. Rekka-auton suurin sallittu korkeus kuorman kanssa on 4,2 m ja kuorman tehollinen korkeus noin 3 metriä. Eri paalityypeillä kuorma jää korkeudeltaan eri tavoin vajaaksi. Kuormakoot paalien optimaalisella ladonnalla on esitetty taulukossa 1. Irtotavarakuorman massa on korkeintaan 10,5 tonnia. Pyöröpaalikuorman massat ovat 15 - 18 tonnia ja suurkanttipaalien $20-22$ tonnia. Paalien tiheyttä tulisi edelleen lisätä. Toinen vaihtoehto on optimoida paalien kokoa, mutta tämä edellyttäisi uusien paalainten kehittämistä.

Taulukko 1. Helpikuormien massat rekka-autossa.

\begin{tabular}{|l|l|l|l|}
\hline & Paaleja & Paali-m & Massa, $\mathrm{t}$ \\
\hline Irtotavara & & 150 & 10,5 \\
\hline Pyöröpaali 1,2 m & $60-64$ & $81,4-86,9$ & 14,7 \\
\hline Pyöröpaali 1,5 m & $48-52$ & $101,8-110,3$ & 18,3 \\
\hline Suurkantti 1,2×0,7×2,4 m & $60-66$ & $121-133,1$ & 21,8 \\
\hline Suurkantti 1,2×0,9×2,4 m & $44-50$ & $114-129,6$ & 20,5 \\
\hline Paikallispaalain ${ }^{1)}$ & 98 & 101,8 & 28,5 \\
\hline 1) Orkel-paikallispaalaimella tarkkuusilputusta helvestä tehtyjä paaleja
\end{tabular}

Ruokohelven kaukokuljetuksen kustannukset on esitetty kuvassa 1. Suurin kustannus on irtotavaran kuljetuksessa. Paalien kuljetuksen kustannukset ovat alhaisempia, mutta vielä korkeampia, kuin jos kuormilla saavutetaan rekka-auton täysi kantavuus. 


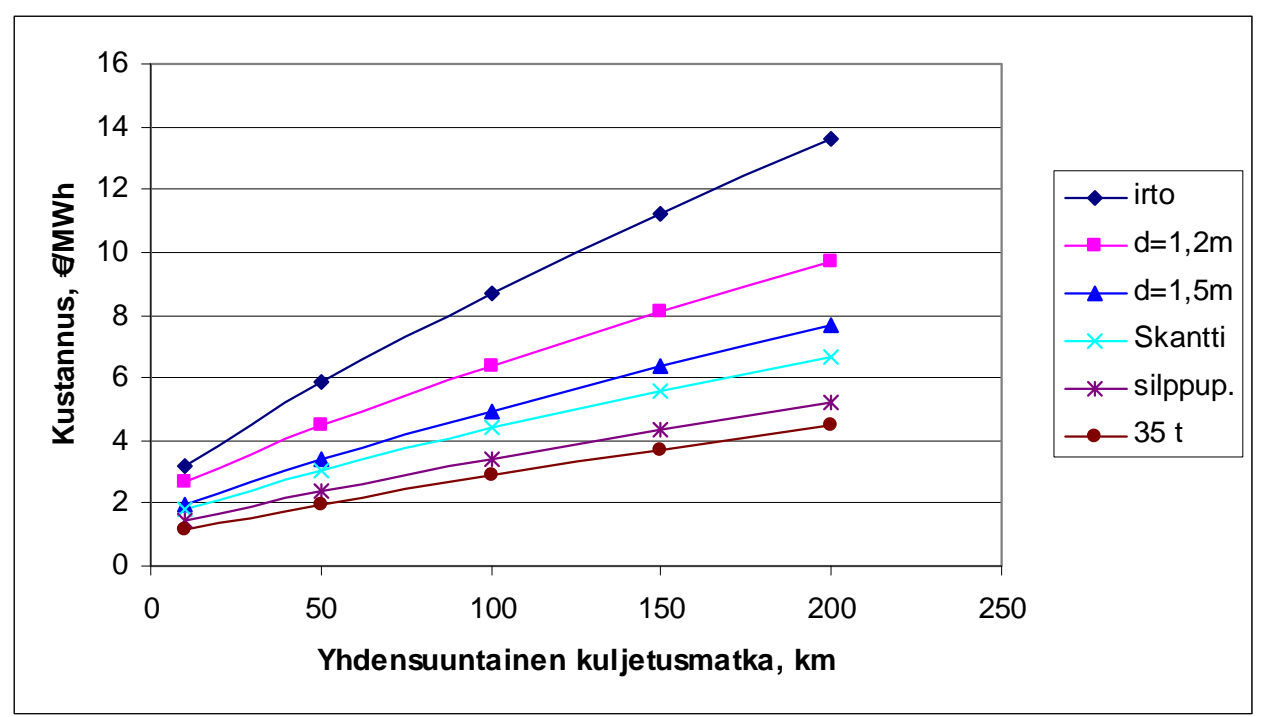

Kuva 1. Ruokohelven kaukokuljetuksen kustannukset.

\section{Ruokohelven murskaus}

Kokonaisena korjattujen ruokohelpipaalien murskaukseen voidaan käyttää erityyppisiä koneita (Paappanen et.al., 2007). Tavoitteena on saada silppua, jossa silpun pituus on lyhyttä, valtaosaltaan selvästi alle $10 \mathrm{~cm}$. Pitkä silppu holvaantuu helposti nykyisillä voimalaitoksen käsittelylaitteistoilla.

Nopeakäyntiset hakkurit ovat vasaramurskaimia tai rumpuhakkuri-tyyppisiä, jotka ovat kiinteitä asennuksia tai liikuteltavia versioita. Laitteiden kapasiteetti on suuri (jopa 30 tonnia tunnissa), ja paalinarut eivät aiheuta ongelmia, mutta pölyäminen voi olla ongelma. Puoliperävaunun alustalle rakennettujen murskainten liikkuminen teiden ulkopuolella on vaikeaa. Laitteiden hinnat ovat $300000-$ $600000 €$.

Kaukalomurskaimissa on halkaisijaltaan 2 - 3,5 metrinen vaakatasossa pyörivä lieriö, jonka pohjalla on nopeasti pyörivä roottori. Silppu on lyhyttä ja paalinarut eivät aiheuta ongelmia. Laitteella voidaan murskata samanaikaisesti puuta ja helpeä, jolloin saadaan valmis polttoaineseos. Pölyäminen voi olla ongelma voimalaitosympäristössä.

Maatalouden paalisilppurit ovat hinnaltaan edullisia laitteita $(20000-30000 €)$, mutta niiden kapasiteetti on 5 - 10 tonnia tunnissa. Jotkut laitteista on suunniteltu oikeastaan vain purkamaan paali, jolloin silppu on pitkää. Jotkut urakoitsijat ovat lisänneet terien lukumäärää ja pyörimisnopeutta, jolloin silpun pituutta on saatu lyhennettyä. Paalinarut kietoutuvat terärummun ympärille ja ovat joissakin malleissa vakava ongelma, ja parhaimmissakin laitteissa naruja joudutaan aika-ajoin poistamaan. Myös pölyäminen on ongelma.

Muutamilla voimalaitoksilla on Suomessa hidaskäyntinen, kiinteä murskain, joka on tarkoitettu pääasiassa hakkuutähteen ja vastaavan puuaineksen murskaukseen. Kuivat paalit hitaasti syötettynä menevät läpi murskasta ja sen jälkeisestä linjastosta. Silppu on pidempää kuin nopeakäyntisten murskainten, mutta lyhyempää kuin huonoimpien mobiilimurskainten. Murskan kapasiteetti puulla on suurempi kuin helvellä, jolloin helven murskaus on perusteltua silloin kun murskalla on ylikapasiteettiä. Sinänsä murskauksen hinta on pienempi (noin $2 € / \mathrm{MWh}$ ) kuin mobiilimurskaimilla (noin $3-4$ €/MWh).

Tanskassa joillakin olkea polttavilla laitoksilla käytetään erityisesti tähän tarkoitukseen suunniteltua hidaskäyntisiä paalisilppureita, joiden hankintahinta on pienempi (60000 €) kuin kiinteiden voimalaitosmurskainten. Paalit asetetaan syöttöpöydälle perättäin, jonka jälkeen automatiikka murskaa helpeä käyttötarpeen mukaan. Murskaimessa on rumpu, jossa on kiinni teräpaloja, joten rakenne on lähes sama kuin kiinteissä voimalaitosmurskissa. Tämän tyyppinen murskain asennetaan Kokkolan Voima Oy:n laitokselle vuoden 2007 lopulla. 


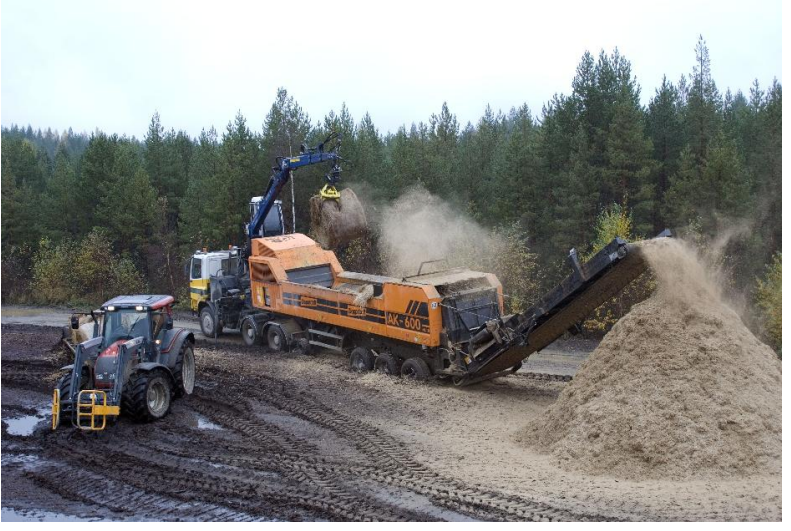

Kuva 2. Doppstadt vasaramurskain.

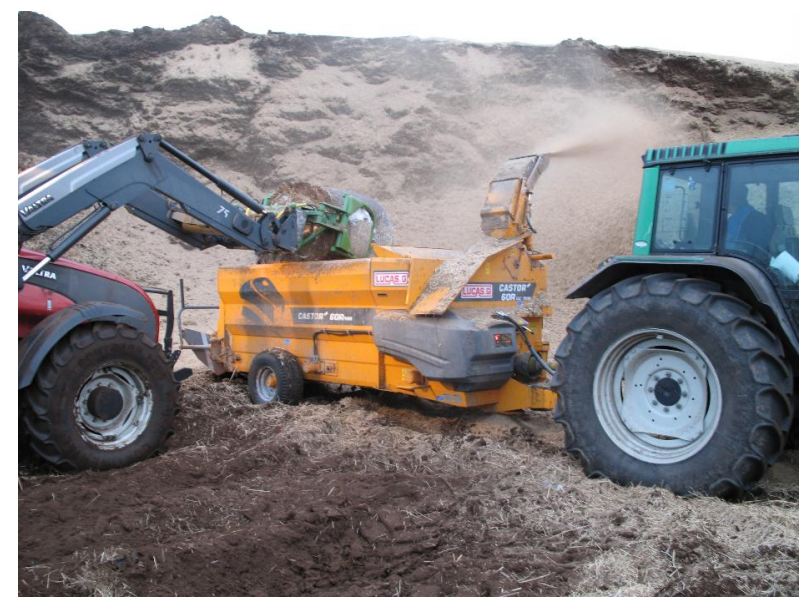

Kuva 4. Helvelle soveltuva maatalouden paalisilppuri.

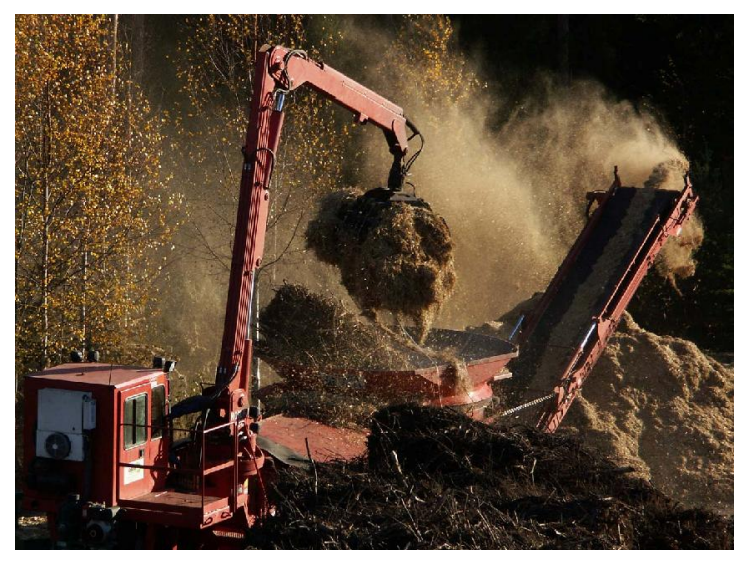

Kuva 3. Morbark kaukalomurskain.

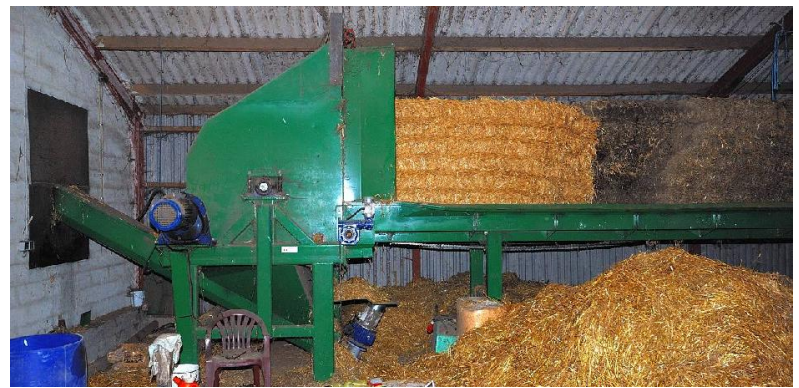

Kuva 5. Hidaskäyntinen kevyt murskain.

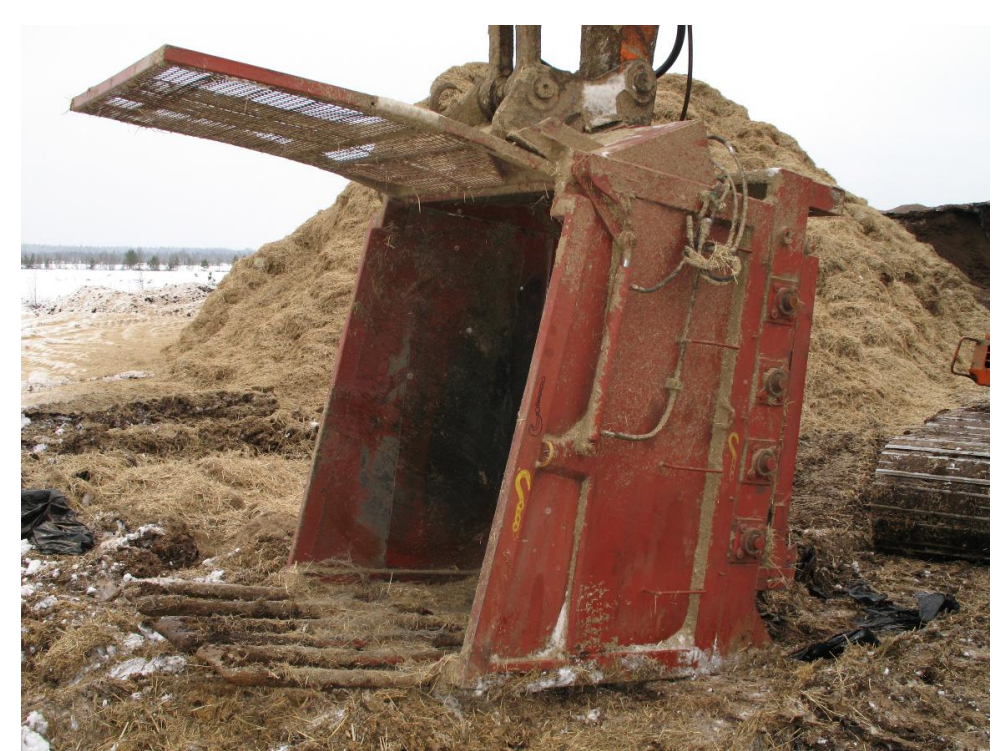

Kuva 6. Kehitteillä oleva kaivinkoneeseen asennettava murskain, jossa murskaukseen tarvitaan vain yksi kone ja yksi työntekijä. Silppu on kohtalaisen lyhyttä ja paalinarut eivät ole ongelma. 


\section{Ruokohelven käyttö voimalaitoksilla}

\section{Käyttöpotentiaali voimalaitoksilla}

Ruokohelven polttoon soveltuvia suurempia voimalaitoksia on Suomessa noin 50 (Flyktman, Paappanen, 2005). Lisäksi pelkästään lämpöä tuottavia pienehköjä leijupetikattiloita on noin 25 kappaletta. Kun helven energiaosuudeksi oletetaan $10 \%$ kaikesta laitosten käyttämästä kiinteästä polttoaineesta, on helven käyttöpotentiaali voimalaitoksissa noin 4,1 TWh, mikä viljelypinta-alana on 140000 - 190000 ha. Lisäksi helpeä voitaisiin käyttää pelletin raaka-aineena noin $1 \mathrm{TWh}$. Yhteensä helven käyttöpotentiaali on siis 5,1 TWh, mikä on pinta-alana $170000-230000$ ha.

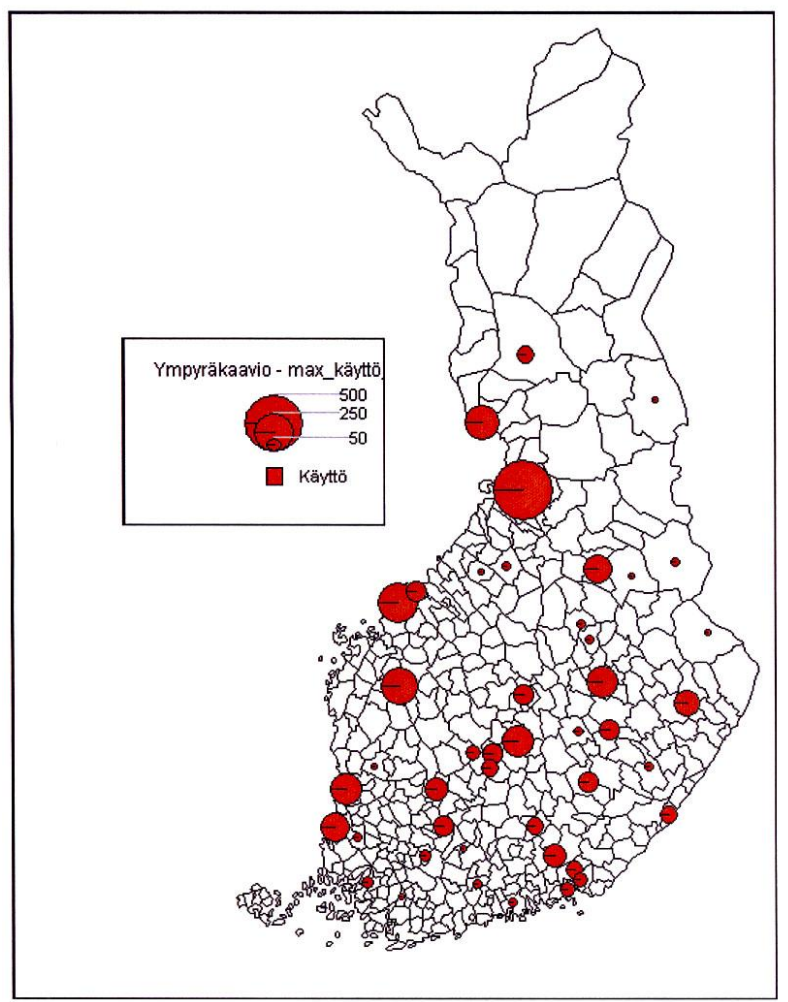

Kuva 7. Helven käyttöpotentiaali voimalaitoksissa $(G W h / a)$.

\section{Käyttökokemuksia voimalaitoksilla}

Suomessa on arvioitu olevan nykyisin 70 - 80 voima- ja lämpölaitosta, jotka voivat käyttää ruokohelpeä seospolttoaineena. Yli 20 voimalaitoksella on jo kokemusta ruokohelven soveltuvuudesta energiantuotantoon (Impola et. al., 2007). Tehdyn kyselyn perusteella ruokohelven käyttö laitoksissa oli alle $30 \mathrm{GWh}$ vuonna 2006. Hetkellinen maksimiosuus on $10-15 \%$ energiasisällöstä ja keskimääräinen osuus $1-3 \%$. Helven käyttöä kokeilevat laitokset ovat ottaneet helven yleensä valmiiksi turpeeseen sekoitettuna. Laitokset joilla on käyttöpaikkamurskain, ovat voineet hyödyntää sitä myös helven murskauksessa. Käytön ensikokemusten perusteella ruokohelpi ei ole aivan ongelmaton polttoaine. Seuraaviin ongelmakohtiin kiinnitettiin huomiota:

- Liian kostea helpi tarttuu kolakuljettimiin ja myöskään murskaustulos ei ole hyvä

- Pölyäminen on ongelma käytettäessä nopeakäyntisiä murskaimia voimalaitosalueella, aiheuttaa siivoustarvetta ja on turvallisuusriski

- Alhainen helven irtotiheys laskee kuljettimien kapasiteettia täydellä kuormalla ajettaessa

- Useilla laitoksilla jyrsinturpeelle mitoitettu kiekkoseula vie ylitteeseen liikaa helpeä, mistä aiheutuu ylitemurskan ylikuormitus

- Murskattu helpi ei läpäise vastaanottotaskun päällä olevaa ritilää, ei aina edes seoksena. Pitkä helpi holvaantuu ja tukkii kuljettimia. Ongelmat vähentyvät kun puuta ja helpeä murskataan oikeassa suh- 
teessa samanaikaisesti. Yleinen kommentti oli: "Kyllähän helpikin palaa kattilassa ilman ongelmia, kun sen saa sinne syötettyä”.

- Useilla laitoksilla on oletus, että käytettäessä helpeä nykyistä suuremmilla osuuksilla kattiloiden lämpöpintojen likaantuminen ja kuumakorroosioriski tulevat lisääntymään.

- Ruokohelven osuuden määrittäminen päästökauppaa varten tulisi olla luotettavaa.

Tanskassa olkea käytetään laajamittakaavaisesti ja ympärivuotisesti hiilen kanssa polttoaineena. Siellä on muun muassa voimalaitoksia, joissa olki siirretään pneumaattisesti kattilaan ohi muun kiinteän polttoaineen käsittelyjärjestelmän. Tämä voisi ratkaista monia ongelmia suomalaisissa voimalaitoksissa. Pneumaattista syöttöä on tarkoitus hyödyntää Kokkolan Voima Oy:n voimalaitoksella loppuvuodesta 2007. Tanskassa korjuu tapahtuu pääasiassa Heston paaleina. Viljelijät säilyttävät paalit usein katetuissa varastoissa. Rekka-autot puretaan tietokoneohjatuilla nostureilla kahdella kouraisulla. Paalit sijoitetaan voimalaitoksen varastoon, ja samalla määritetään paalien kosteus nosturissa olevilla mikroaaltoantureilla. Sama nosturi siirtää paalit syöttökuljettimille. Paalinarut katkotaan ja tarvittaessa kerätään pois automaattisesti. Arinakattiloihin olki syötetään pitkänä, pneumasyöttöön olki on jauhettava hienommaksi.

\section{Ruokohelven tuotannon kustannus}

Ruokohelven tuotanto- ja toimitusketjun kokonaiskustannus muodostuu viljelystä, vuosilannoituksesta, korjuusta, mahdollisesta paalien murskauksesta, kaukokuljetuksesta ja viljelymaan arvosta. Nämä kustannukset irtokorjuulle ja pyöröpaalaukselle on esitetty kuvassa n (Pahkala et.al., 2005). Helven satotasoksi on oletettu $6 \mathrm{t}_{\mathrm{ka}} / \mathrm{ha}$ ja kaukokuljetusmatkaksi $70 \mathrm{~km}$. Suurin yksittäinen menoerä on pellon arvo. Paaliketjussa paalien murskauksen kustannus on suurehko ja irtotavaralla vastaavasti helven kaukokuljetus.


Kuva 8. Ruokohelven tuotanto- ja toimitusketjun kustannukset pyöröpaaleille ja irtotavaralle.

Ruokohelven viljelyn kannattavuutta ja voimalaitoksen maksamaa hintaa on arvioitu taulukossa 2. Oletetaan, että helpi korjataan pyöröpaaleina ja toimitetaan laitokselle, jossa paalit murskataan laitoksen kiinteällä murskalla. Viljelijän kustannukset pellolla tapahtuvasta työstä ja kaukokuljetuksesta ovat noin $24 € / \mathrm{MWh}, 680 € / \mathrm{ha}$. Oletetaan viljelijän saavan voittoa toiminnasta $0-170 € / \mathrm{ha}(0-6$ $€ / \mathrm{MWh})$. Tällöin viljelijän kokonaiskustannukset ovat $680-850 € / \mathrm{ha}(24-30 € / \mathrm{MWh})$. Viljelijän saamat tuet $\mathrm{C} 2$-tukialueella ovat $593 € /$ ha. Tällöin kustannusten peittämiseksi on viljelijän saatava voimalaitokselta hinta, joka on noin $90-260 € /$ ha $(3-9 € / \mathrm{MWh})$.

Taulukko 2. Ruokohelven tuotannon kannattavuuden arviointia.

\begin{tabular}{|l|c|c|}
\hline & $€ / \mathrm{ha}$ & $€ / \mathrm{MWh}$ \\
\hline Viljely, korjuu ja kaukokuljetus & 680 & 24 \\
\hline Viljelijän voitto & $0-170$ & $0-6$ \\
\hline Kustannukset yhteensä & $680-850$ & $24-30$ \\
\hline & 593 & 21 \\
\hline Maataloustuet & & $3-9$ \\
\hline $\begin{array}{l}\text { Kustannukset - tuet (=voimalai- } \\
\text { tokselta saatava hinta) }\end{array}$ & $87-257$ & \\
\hline
\end{tabular}


Voimalaitos joutuu helven ostohinnan lisäksi maksamaan helven murskauksen kustannuksen, joksi on arvioitu $2 € / M W h$. Voimalaitos hyötyy päästökauppatilanteessa helven käytöstä, mutta hyöty riippuu voimalaitoksen polttoainevalikoimasta. Jos helvellä korvataan kivihiilen tai turpeen käyttöä, ja päästöoikeudella on marginaalista suurempi kustannus, voi voimalaitos pystyä maksamaan helvestä edelllä mainitun hinnan, jopa enemmänkin. Kasvanut helven osuus nostaa todennäköisesti kattilan käyttökustannuksia (mm. leijuhiekan vaihtotarve, likaantumishaitat, ylimääräiset huoltoseisokit, jne), jolloin helven tuomat kustannussäästöt voivat helposti kadota.

\section{Johtopäätökset}

Ruokohelven käyttö voimalaitoksissa on voimakkaasti lisääntymässä. Helven tuotanto- ja toimitusketjua on kehitetty, mutta teknisiä ratkaisuja ja toimintatapoja voidaan vielä tehostaa. Suurimmat kehityskohteet ovat korjuutappioiden pienentäminen, kaukokuljetuksen tehostaminen, paalien murskauksen kehittäminen (silpun laatu ja murskauksen kapasiteetti) sekä voimalaitosten tekniikan ja toimintatapojen parantaminen.

Helven kaukokuljetuksessa paaleillakaan ei saavuteta rekka-auton täyttä kantavuutta. Korjuuseen käytettävä pyöröpaalain tulisi olla muuttuvakammioinen. Eräiden havaintojen mukaan suurkanttipaalaimella saadaan tiiveimmät paalit. Paalien tiheyttä tulisi kuitenkin edelleen lisätä. Toinen vaihtoehto on optimoida paalien kokoa, mutta tämä edellyttäisi uusien paalainten kehittämistä.

Paalien murskauksen neljä ongelmakohtaa ovat murskainta tukkivat paalinarut, pitkä silpun pituus, pölyäminen ja murskauksen kustannus. On olemassa murskaimia, joissa teknisen ongelmat on voitu ratkaista, mutta murskaus on suhteellisen kallista. Halvimmillaan murskaus voidaan tehdä voimalaitoksen kiinteällä murskalla, mutta tällöin murskain on pois puun murskauksesta, jossa se on tehokkaimmillaan.

Voimalaitokset ovat aloittamassa ruokohelven käyttöä polttoaineena. Käytön ensikokemusten perusteella ruokohelpi ei ole aivan ongelmaton polttoaine, koska se on kevyttä verrattuna muihin polttoaineisiin. Erilaiset tukkeentumiset ja holvaantumiset ovat ongelmana. Pienestä energiatiheydestä johtuen helpeä ei aina voida käyttää maksimitehon aikana, ja helven epäillään likaavan ja syövyttävän kattiloita. Helven käsittelyyn liittyvät ongelmat ovat laitoskohtaisia, joissakin laitoksissa helpi ei ole aiheuttanut ongelmia, mutta toisissa jo pienetkin helpimäärät on sekoitettava hyvin pääpolttoaineeseen. Yksi ratkaisu ongelmiin voi olla Tanskan mallin mukainen hidaskäyntinen, kevyt murskain ja pneumaattinen siirto kattilaan. Tätä on tarkoitus kokeilla Kokkolan Voima Oy:n voimalaitoksella loppuvuodesta 2007.

Ruokohelpi on uusiutuva biopolttoaine. Maataloustukien kanssa sen tuotanto voi olla vaihtoehtoinen tuotantomuoto maanviljelijälle. Korvattaessa helvellä kivihiiltä tai turvetta voi voimalaitos päästökauppatilanteessa maksaa helvestä teoriassa hyvinkin korkean hinnan olettaen, että helven käyttö ei aiheuta ylimääräisiä kustannuksia.

\section{Kirjallisuus}

Flyktman, M., Paappanen, T. 2005. Ruokohelven käyttökapasiteettiselvitys. Tutkimusselostus PRO2105/06. VTT Jyväskylä.

Impola, R., Kärki, J., Leino, T. 2007. Ruokohelven käyttöselvitys voimalaitoksilla. Tutkimusraportti VTT-R-03717-07. VTT Jyväskylä. (Luottamuksellinen)

Paappanen, T., Impola, R., Kärki, J., Rinne, S. 2007. Ruokohelven käyttömahdollisuudet Rauhalahden voimalaitoksessa. Tutkimusraportti. VTT Jyväskylä. (Luottamuksellinen)

Pahkala, K., Isolahti, M., Partala, A., Suokannas, A., Kirkkari, A-M, Peltonen, M., Sahramaa, M., Lindh, T., Paappanen, T., Kallio, E., Flyktman, M. 2005. Ruokohelven viljely ja korjuu energian tuotantoa varten. 2. korjattu painos. ISBN 951-729-943-5. Maa- ja elintarviketalouden tutkimuskeskus. 